Short-term global business immersion courses:

Short-term program, long-term effects?

\author{
Keith Gelarden Dayton* \\ Karleigh Koster \\ Jamie D. Prenkert \\ Robert Ridlon \\ all of \\ Kelley School of Business \\ Indiana University \\ 1309 E. Tenth Street \\ Bloomington, IN 47405 \\ U.S.A.
}

*Corresponding author kedayton@indiana.edu 


\title{
Short-term global business immersion courses: Short-term program, long-term effects?
}

\begin{abstract}
This article explores the potential impact of short-term global business immersion courses designed for undergraduate students at the Indiana University Kelley School of Business. As part of the Global Foundations Core curriculum, the school offers students a unique opportunity to study a country or region in depth in the classroom and then participate in an accompanying short-term study program abroad. In this article, multiple Kelley faculty who teach global immersion courses offer context-specific strategies and insights into classroom teaching and observed outcomes for student learning. Research shows that short-term study-abroad programs can offer transformative opportunities for students when intentionally designed as part of curriculum, affecting attitudes toward environmental citizenship and shaping global careers. The Chronicle of Education reports that even short study-abroad programs can have a lasting effect. To date, the Kelley School has not measured for standardized learning outcomes across its 14 existing global immersion courses, so this article does not offer commentary on program-wide student learning. However, through analyses of their on-campus course design and respective overseas program activities, Global Business Immersion program faculty share insights into student learning as observed in their individual programs. Our intent is to capture the impact of the courses through the lens of faculty program directors and student participants in three programs across three continents. In addition, we contribute to future research on similar global academic initiatives and add to the expanding body of knowledge on the impacts of short-term study abroad.
\end{abstract}

KEYWORDS: Country analysis; Global immersion; International business education; Shortterm study abroad 


\section{Introduction to global immersion programs}

In 2012, as part of a total revision of its undergraduate curriculum, Indiana University's (IU's)

Kelley School of Business introduced the Global Foundations Core: a set of four courses designed to introduce students to the global nature of business and global business enterprises. Required of all students and typically taken during the second year of study, the four courses are the signature experience of the sophomore year. Though Kelley already offered a co-major in international business prior to the 2012 curriculum revision, the new Global Foundations Core was deliberately created to expose all Kelley students - not just those with the declared comajor-to topics in international business and to do so early in their business studies. By developing the Global Foundations Core for all second-year students, the Kelley School was then able to expand and advance the content of the International Business core courses, thus adding academic depth for students pursuing the co-major while also integrating international business into the curriculum for all students.

The goal of the Global Foundations Core is to introduce strategies to analyze and interpret the economic, social, political, legal, cultural, and technological influences that drive the global economy. Global Business Environments (BUS-D270) is a 1.5-credit course designed to familiarize students with the environments facing managers and corporations operating in the global economy. After D270, students take either Global Business Analysis (X271), an 8-week on-campus course, or Global Business Immersion (X272), an 8-week on-campus course that is followed by an 8-10 day international program in which the entire class of students, faculty, and staff travel together to the country they have been studying and ends with a deep experiential learning opportunity. In both X271 and X272, students learn to apply the dimensions of D270 into a unique analysis of a specific country. Business, Government, and Society (BUS-G202) comprises the fourth course of the Global Foundations Core.

The overseas components of X272 are collectively called Global Immersion Programs. Each course undertakes an analysis that explores the economic, social, political, and technological dimensions of a specific nation and their effects on business. During 8 weeks of class meetings on campus in Bloomington, IN, students in X272 courses explore culture (the social dimension), markets (the economic dimension), power (the political dimension), and innovation (the technology dimension) under conditions of global interdependence. The interrelationships among all the dimensions are crucial for effective business-strategy formulation. Though X271 courses also undertake country analyses and investigate the multifaceted implications for international business, the international component of the X272 Global Business Immersion courses was deliberately designed to allow students to delve deeper into a specific country or region and apply their classroom analysis on site in the country of study. This is carried out through a program of business and government visits, meetings with institutional actors, reflective activities that link classroom content to in-person experiences, and excursions to important cultural sites.

When the Global Immersion Programs were introduced in 2012, the Kelley School's long-term goal was to develop a changing portfolio of X271 and X272 course offerings in which content would build on D270 and G202, while capitalizing on the increasing diversity and international expertise of the school's faculty. The first group of X272 courses took place in 2014 and comprised seven options. By 2018, this roster grew to 15 courses that offer a business-focused, 
short-term study-abroad program to nearly 400 Kelley undergraduates. In the first 5 years of X272 program offerings, over 1,300 Kelley students traveled abroad with faculty experts on 57 business study tours to five continents.

Study-abroad programs that offer a domestic classroom experience as well as an international component are a growing phenomenon in the field of international education programs that allow universities to link study-abroad content with institutional curriculum, while also tapping into faculty expertise for program leadership. Due to the dual nature (i.e., classroom study followed by international experiential learning), programs of this type require different pedagogical approaches and classroom activities and have a different set of learning goals than a course in which content exists primarily in a classroom. To design an X272 program, faculty must balance classroom objectives with objectives for the international experiential component, creating a structure in which all classroom content is designed to prepare students for their time overseas, while the overseas activities regularly refer back to classroom content.

\section{Studying business in Cuba, Korea, and South Africa}

For at least 3 years, Kelley's Department of Communication, Professional, and Computer Skills; Department of Business Economics and Public Policy; and the Department of Business Law and Ethics have offered X272 programs in Cuba, Korea, and South Africa, respectively. Given the varying histories, cultures, and business environments of the three countries, the starting point for each course was different for each program director.

\subsection{Cuba}

Until recently, the very idea that Cuba could host a short-term study-abroad program was somewhat inconceivable; longstanding strained relations between the U.S. and Cuba created an environment of political posturing, lack of communication, and barriers to physical access, all of which blocked academic investigation. Over the past few years, other student groups from IU have ventured into Cuba with promising academic and experiential results; for example, IU's School of Public and Environmental Affairs (SPEA) now travels to Cuba to study history, culture, and foreign policy in effort to understand both Cuba's system of governance and social programs, and how Cuba's economic and political model compares to that of the U.S. It is notable, however, that prior to 2014, no undergraduate business program studied in Cuba.

The business element and intent of this suggested a Kelley School of Business program in Cuba had little parallel to other academic endeavors. The pedagogical focus of the Kelley program was twofold: (1) studying the discipline of business in Cuba and collaborating with small Cuban businesses in the new emerging market and (2) developing a deeper understanding of the economic, social, political, legal, cultural, and technological influences that drive the global economy and investigating them in the specific context of the emerging Cuban business environment. To reach those goals, students would need to collaborate with existing privatesector businesses in Cuba, first by examining their current business practices and then-based on analysis of the general business environment and the specific business's needs - offering recommendations in collaboration with the business owner. This combined effort, which takes into account the opportunities and constraints facing the business, enhances the ownership's business skills while developing the students' own growing business skills in a real-world 
setting. This course provides students the opportunity to use many of the skills they acquired via their academic experience at IU and offers them significant learning opportunities to work in collaboration with an emerging international economy, assisting career development as well as personal growth.

Before studying businesses operating in Cuba, students had to understand the development of Cuban business. In the last 60 years, Cuba has undergone extreme commercial and cultural changes because of the political regime of Fidel Castro that reshaped the country's economic environment. The downfall of the Soviet Union forced Cuba into the Special Period in the early 1990s, further exacerbating the pressure on the Cuban marketplace. As explained by Benzing (2005, p. 69):

Since 1989, Cuba has struggled to recover from the loss of Soviet trade and subsidies. The Cuban government dubbed the period between 1990 and 1994 "A Special Period in Peacetime" in recognition of the $35 \%$ decline in GDP. Instead of restructuring its economy, the Cuban government used a Band-Aid approach that permitted selfemployment, raised prices, legalized the dollar, and decreased government subsidies of state enterprises. Although growth resumed in 1994, the Cuban economy never fully recovered to pre-1989 levels of GDP.

More recently, the economic downturn in Venezuela, Cuba's current major subsidizer, further heightened the need for the country to seek other revenue sources (Riera \& Swinnen, 2016). Fidel Castro's 2006 handover of governance to Raul Castro signaled new changes in economic policy to compensate for the loss of revenues (de Miranda-Parrondo, 2014). These changes paved the way for an expansion of the private business ownership that existed in Cuba since the 1990s. At that time, the Cuban government allowed only two specific businesses to be run privately: Paladares, which are family-owned restaurants; and Casas particulares, which rent rooms to tourists. After the 2006 handover of power, the Cuban government licensed new opportunities for private ownership beyond the Paladares and Casa particulares. For the Cuban wanting or needing additional revenue, this change dramatically increased the ability to gain more economic resources beyond government subsidies. Phillips (2007, p. 306) described the new Cuban entrepreneurs since the policy change: "Cuentapropistas remain one of the most potent symbols of Cuba's changing economy, political, and ideological character in part because of the significance outside observers have attached to their existence." The clear difference is that individuals exclusively own their respective businesses, taking away most state restrictions. This was the first time since the end of the Cuban Revolution in 1959 that Cubans enjoyed private ownership of businesses.

These changes, coupled with the recent opening of the diplomatic relationship between Cuba and the U.S., accelerated the return of American business interests into the Cuban economy. In addition, the restoration of diplomatic relations (including embassies opened by both governments) opened the door for new and different kinds of academic programs in Cuba. Under these circumstances, Kelley faculty saw an opportunity to develop a short-term study-abroad 
program designed for students to study business in the rapidly changing Cuban economy. For the students, they were able to participate in a historical and political landscape that would enhance their understanding of the global economy.

\subsection{Korea}

Korea, on the other hand, has a long history with the U.S. as well as longstanding but shifting relationships with its regional neighbors. Located on a peninsula between China and Japan, Korea has experienced significant foreign influence throughout much of its history. Most notably, the end of the civil war between North and South Korea that involved many outside powers caused a renewed focus on economic development and engagement with the outside world. While North Korea pursued communism in close connection with fellow communist countries China and the Soviet Union, South Korea pursued a democracy with the primary support of the U.S. The Global Immersion course there focuses on how South Korea has pursued economic development, moving from a predominantly agriculture-based economy to become a global player in trade and innovation.

\subsection{South Africa}

The Global Immersion program in South Africa uses human rights and international law as the starting point for business analysis. The course is based on the foundational principle that business students are preparing for careers in an environment marked by globalization and dominated by multinational corporations, where businesses have an outsized and largely unchecked influence on human rights practices around the world. Because multinational corporations span national, regional, and continental boundaries, effective human rights enforcement is difficult without any given country risking extraterritorial overreach. In the classroom, students in Business and Human Rights in South Africa first learn the important history of the United Nations Human Rights Commission's establishment of a special representative of the secretary-general on the issue of human rights and transnational corporations and other business enterprises (SRSG). The SRSG was created with a mandate to identify and clarify corporate responsibility and accountability standards for businesses with regard to human rights. A key development of the SRSG is the Protect, Respect, and Remedy (PRR) framework and the Guiding Principles on Business and Human Rights (guiding principles) to address and fill governance gaps.

The travel component of the course in Johannesburg, South Africa provides students the opportunity to observe and assess efforts to incorporate the respect prong of the PRR framework. They also study the guiding principles in the unique context of a mature business environment within an otherwise developing country and region, still influenced by the continuing reverberations of the racially repressive system of apartheid and the subsequent development of one of the world's most progressive democratic constitutions. In particular, students consider the role of business in creating and perpetuating the evils of apartheid, as well as the role of business in the subsequent human rights successes and failures in the post-1994 rainbow nation of South Africa.

\section{Course development and content}


Given these varying points of departure for the three courses, each instructor had significant flexibility in developing course content and goals while still adhering to the stated objectives of the Global Immersion structure. In designing their programs, the faculty who taught these courses worked within different business cultures, created course content based on different business needs, and focused on separate business questions, but did so all under the same umbrella of X272 country-specific business analysis and immersion. As such, the courses take on different forms while also sharing commonalities.

In Cuba, the primary idea for the course was that students would work directly with Cubans to solve problems related to the business issues that arise in a fast-changing emerging economy. Though this was the first Cuban endeavor of the Kelley School to work in collaboration with businesses in Cuba, the Catholic Church had been working directly in Cuba for some time through a program called Proyecto Cuba Emprende. By the end of 2016, this program graduated approximately 3,000 entrepreneurs and supported the launch or acceleration of over 1,500 businesses. ${ }^{1}$ However, the X272 Kelley program would be the first time individuals from a U.S. undergraduate academic institution would work directly with Cuban businesses. There were three overarching goals of the course:

1. Introduce strategies to analyze and interpret the economic, social, political, legal, cultural, and technological influences that drive the global economy through the context of the emerging Cuban business environment;

2. Engage with current private-sector businesses in Cuba by employing relevant business practices and teaching the ownership business skills; and

3. Allow students to gain relevant experience through their interactions with Cuban businesses, assisting their career development and growth.

The design of the 8-week course was to develop an understanding of the Cuban economy, businesses, and culture in preparation for an 8-day visit to Cuba. Throughout the 8-week term and during the subsequent in-country experiences, class members participated in small teams. Each team was assigned to work with two projects: (1) a multinational company seeking market entry into Cuba and (2) an organization currently in Cuba. Students were responsible for completing a specific country analysis for the multinational company, which first required proposing a scope of work to engage in client communications and delivering a final presentation. The country analysis required that students chose a PEST, PESTEL or PESTLE framework (Peng \& Nunes, 2007). For the organization in Cuba, students worked one-on-one with the participating faculty member to gain insight into the specific report necessary to complete the project.

${ }^{1}$ http://www.cubaemprendefoundation.org/ 
The X272 course in Korea focused on how South Korea pursued economic development over the past 50 years, moving from what had been an agriculture-based economy to into a global player in business - home to internationally recognized businesses such as Samsung, Kia, and Hyundai. The course had four primary learning components to understand Korea's economic development. First, students learned to identify the natural and geographical attributes South Korea possesses compared to other East Asian countries and how those affected the country's economic development. Second, students reviewed general economic-development theories and models. Third, students assessed business outcomes in Korea specifically, evaluating business development in terms of economic performance as well as cultural change. Finally, students developed an understanding of the global economic position of South Korea and evaluated how foreign firms should engage with the country through public and private sectors. The course also examined Korean history, focusing especially on the North-South divide and related tensions, politics and the development of democracy in South Korea, and significant cultural elements that affect business practices in the country.

In the course on Business and Human Rights in South Africa, students learn about this history and the current international focus on implementing the PRR framework and guiding principles in business operations through due diligence and human rights impact assessment protocols. Students also explore specific industries and business sectors-like mining, banking, and finance — which raise specialized challenges.

The goals for student learning in the South Africa course are twofold. First, students gain a clear understanding of the responsibility of businesses to respect human rights and to incorporate remedial processes for human rights violations. They accomplish this goal by understanding the legal, economic, technical, and political dimensions of the responsibility to respect, as represented in the PRR framework and guiding principles. Students are ultimately able to analyze a human rights risk within the context of a particular company, articulate the potential impacts of that risk, describe ways to manage it, and provide remedies for those who have been affected. Second, students become more aware globally and culturally by learning about South African history, culture, economics, politics, and social movements. In doing so, students are able to apply their knowledge of business and human rights in the South African context and engage in challenging, thoughtful, and culturally sensitive conversations.

A study-abroad program that comprises both a classroom component and a short-term international travel component must confront the challenges inherent to the structure. These challenges include but are not limited to: (1) generating interest in studying an unfamiliar location, (2) engaging students in academic content when their interest in the course is often tied to the travel itself, and (3) designing a course that connects the at-home content with the overseas business and cultural immersion. Ideally, the overseas travel component is an experiential means to understand the concepts taught in the classroom more thoroughly. While the objectives of X272 programs differ, they all take on a three-part structure: a series of deliverables as part of the on-campus classroom portion of the course; activities and assignments during the in-country visit; and reflection after the course is completed. The X272 model relies on immersion in a culture to provide a greater depth of understanding for the student. As identified by Kuh (2008) and the American Association of Colleges and Universities, high-impact educational experiences 
that incorporate global learning and field-based experiential components are linked to increased rates of undergraduate student learning and engagement.

\section{Course deliverables and student learning outcomes}

\subsection{Cuba}

In order to achieve learning objectives, the eight weekly class sessions in the course entitled Cuban Business: A New Frontier involved discussion, research, presentations, guest speakers, and group work. In addition, students were required to find a relevant popular press article on Cuba and post an overview of the article on Slack (i.e., a cloud-based collaboration platform) in order to start a dialogue with their peers, to investigate online articles about the country of Cuba, to read weekly selections posted by the instructor, and to maintain a journal of their experience through a written or visual medium. The program used multiple assessment tools to measure the student experience in the class, during the travel component, and after the course ended. Assessment included evaluations of posted article overviews on Slack or tweets through an assigned course Twitter account as well as attendance, professionalism, journal submission, and peer evaluation. The instructor also assessed group work through a country analysis, in-country work, and the group's recommendations for either a business in Cuba or U.S.-based market entry by Zimmer-Biomet, an orthopedic company seeking to enter the Cuban business market. While the students' journals served as a reflective tool, the instructor developed a survey after the course to examine student impressions and meaning taken from the experience. Studies have recognized that "study abroad is not simply a private good or individual experience; rather, in encountering themselves, study abroad students bring back home with them perspectives that help shape the future American citizenry" (Tarrant \& Lyons, p. 411). Norris and Gillespie (2009) examined career-related questions to understand the impact of study-abroad programs on future careers.

\subsection{Korea}

The Dynamic Economics in Korea course had four main deliverables: in-class discussions of articles relevant to course content, a team project, a cultural analysis, and a team scavenger hunt. The first three were assigned and prepared by students during the 8-week course on campus, while the scavenger hunt takes place while the group is in Korea.

The article discussions required teams of students to take the lead in class to analyze an article from an academic journal or book chapter related to economic development. All the students were expected to complete the reading, but teams took the lead during in-class discussion and prepared in advance an outline emphasizing the article's main points, implications, and applications to Korea specifically. In this way, students learned fundamental components of economic development and how those theories play out in the country of study. They also developed critical thinking and analytical skills while practicing public speaking and group leadership.

The team project involved assigning to each group a Korean institution (e.g., a university, a business, a cultural organization) that the class visits during the overseas study tour. This project had four main parts: 
1. As a group, each team identified a relevant Korean government agency as well as a foreign company that interacts with their assigned institution. The group carried out a country analysis specific to the assigned industry and institution to describe the economic and business issues affected, while each member took on the role of a stakeholder;

2. Individual team members assessed the industry that is specific to their institution and how this connects to the Korean economy. Students also conducted individual research based on their assigned institution and relevant interlocutors;

3. After the individual write-up and individual analysis, the teams regrouped to synthesize their work, compiling the individual members' analyses into one collective research report and presentation; and

4. After visiting Korea and the institution to which they were assigned, each team revised recommendations as needed to better reflect the perspective gained from in-person experience.

The third course deliverable was the cultural analysis, or haechi. This is an individual presentation to the class on a specific facet of Korean culture. Students chose and researched an aspect of the culture that interested them and then presented to their peers and instructor how and why this aspect was relevant to the course's focus on Korean economics and business. All students were thus exposed to multiple topics and the entire class learned about Korea together.

In the scavenger hunt, the fourth deliverable, teams semi-competitively accomplished certain tasks on site in Seoul. These tasks included finding specific locations within the city and participating in a list of required activities. Teams prepared a final commentary of the scavenger hunt through written work, photos, and videos. The activity provided everyone the freedom to explore an unknown part of the city, requiring students to work together as a team, use problemsolving techniques, and cope with an uncertain environment. Past participants have cited this as the most challenging task not just in the X272 program but in all of college, testing their problem solving and teamwork abilities while allowing them to take risks.

\subsection{South Africa}

The program in South Africa had four main deliverables: an in-class presentation on a significant aspect of South African history, politics, economics, or culture; an analysis and consultation report on human rights risk/impact; a take-home exam; and a learning log. In addition, while in the classroom and overseas, students were expected to contribute to the group dynamic of a 
shared learning community and to participate in informal conversations and debriefs after guest speakers and business visits.

The in-class presentations, like the haechis for the Korea course, were designed to prepare students to be informed travelers in South Africa. Most class sessions began with multiple teams of two students delivering presentations on topics of South African history, politics, economics, culture, society, or social movements.

For the analysis and report, students had to identify and research a human rights risk or impact by a specific business in (preferably southern) Africa. They discussed the risk or impact through the lens of the International Bill of Human Rights, as well as the PRR framework and the guiding principles, with specific attention to the requirement in the guiding principles that companies "know and show" their commitments to respect human rights and remedy negative impacts (UNHRC, 2011). Students were required to evaluate, critique, and offer constructive suggestions for improvement. For the presentations and recommendations, students positioned themselves as consultants who are exhibiting their expertise; they were assessed based on the thoroughness, clarity, and incisiveness of their evaluation and critique of the issue identified. In addition to the presentation, students also wrote a two-page executive summary of the analysis and recommendations.

The take-home exam was a three-question essay exam. One question required them to integrate what they learned about international human-rights treaties and instruments along with the PRR framework and the guiding principles; they were asked to respond to a hypothetical situation that places them in a future workplace scenario in which they must articulate a commitment to the responsibility to respect human rights in the face of financial incentives to ignore it. A second question required them to synthesize the presentations on South African history, politics, economics, culture, and/or society/social movements by identifying and exploring a unifying theme among them. The final question asked the students to reflect on their study of business and human rights in preparation for the travel component of the course. This final question served as a primer for the type of reflection they were required to do in the learning log assignment.

The learning log assignment expects the students — while in South Africa - to take notes during company and cultural visits, memorialize their thoughts and impressions about their experiences, and keep track of questions or quandaries that arise. Students prepared and produced the final log after they returned from South Africa. The log must connect the travel experiences with the main topics covered throughout the classroom portion of the course. The raw materials for the learning log assignment include the class readings, presentations, assignments, in-class learning activities,

and class lectures, which inform and deepen the insights students recorded while in South Africa.

\section{Reality and lessons learned}

After 8 weeks of in-class lessons, readings, and general program preparation, the realities of onsite learning can be challenging for even the most experienced traveler. For instructors, each iteration of the overseas program offers opportunities to adjust, improve, and maintain classroom and overseas content. 
In Cuba, every class session explored different aspects of the reality students would face in the country, including the many dimensions of political, social, economic, cultural, and personal interactions. Moreover, due to political constraints and the fact that the program had no previous model to follow, the intention of the first X272 student group in Cuba to work directly with businesses in Cuba was not fully understood by those on site and was prevented by barriers outside participants' control. The second undergraduate program focused on one larger Cuban business that was not a paladares or casa particulares. We learned that a relationship had to be built with multiple partners in Cuba to realize the original intent of the course.

One participant from the Cuba program wrote that a key takeaway was:

How crucial entrepreneurship and creativity are in business development and growth. Startups and entrepreneurs are heavily influencing the new business frontier developing in Cuba, and it was amazing to witness that firsthand. The entrepreneurs epitomized courage and leadership by leading the charge for change in Cuba.

Another student wrote of learning most about:

The intricacies of Cuban culture-where it's coming from and where it is going. I also learned about some of the economic realities - how the country has struggled to find itself economically — and some of the subtleties of it.

After returning from Korea, students in that course reported on a variety of lessons they learned from the complementary experiences in the classroom and overseas. Some of their comments hit directly upon the learning goals of the X272 Global Immersion programs that aim to prepare students for a career in a globalized business world. One student wrote of the realization that "other cultures can be successful even though they are not run the way America is run." Another described a shift in perspective, writing: "I was able to look at Asia in a different way." A third developed an understanding that business culture "heavily influences the country's culture as a whole. There is no one structure that is best for the economy, but it is always interesting to see how each country is shaped as a result." Summarized one participant: "We truly understand the economics in Korea now because we learned about it firsthand."

Students in the Korea program reported that the haechi assignment was useful because the personal presentation "prepared [them] for what [they] would see in the country," and helped them learn "about different cultural aspects that [they] would later on see in South Korea."

Several reported that this was "the most interesting part of the class." Others believed that the scavenger hunt in Korea was the most memorable component because it provided "free time to do our own exploration" and was "a wonderful opportunity to be able to explore the city and to use our skills to be able to navigate." Though some were "initially overwhelmed by the amount of places we visited," they enjoyed the free-form assignment that offered "a nice break from the other business-related activities." One student reported: 
The scavenger hunt was one of the most fun things I have ever participated in. There were so many skills that we developed during that experience that I never would have done had I not been pushed to do it.

In the South Africa program, students develop self-awareness through the learning log, which requires them to make connections between the theoretical study of business and human rights in the classroom and the experiences on the ground in South Africa. Even the take-home exam requires the students to think in integrative, synthetic, and reflective ways about the in-class portion of the course, and thus directly supports the stated learning goals.

\section{Conclusions}

All X272 Global Immersion programs carry the expectation that students are part of a learning community and will function together as such. This component is foundational to all of the learning goals and builds a strong sense of agency for students to accomplish those goals and a sense of accountability to each other and to the leadership team of Kelley faculty and staff. To create a successful program, faculty directors have to build a sense of community with their hosts and partners, with their colleagues across the leadership team, and with the students. Short-term study-abroad programs are intense experiences with long, busy days and a lot of activity. Students, faculty, and staff have to adapt and learn together, all in an environment that is unfamiliar to most participants.

Most X272 programs also incorporate a variety of formal and informal debriefing sessions while the group is overseas, as a means to digest the day's activities, reflect on the content they have witnessed, and ask questions or explore observations they have made. As the director of the South Africa program noted, students as a whole are better informed and better-prepared travelers and interlocutors with their hosts as a result of the briefing and consequently learn more during the visits. The assigned briefers hone their research skills by investigating the individuals and organizations with whom the group interacts. As part of any X272 program, the debriefing sessions encourage the students to develop agency in their own learning processes and teaches them to respectfully engage with each other about sometimes controversial or ambiguous topics in a culturally-sensitive and professionally-appropriate manner. Whatever form they take (recommendations, case study, etc.), projects related to specific businesses within the host country require the students to integrate all of the learning goals and show they understand how business practices are deeply linked to history and culture in the host country.

Student presentations throughout the semester develop public speaking skills, give students the occasion to select a specific topic to research individually or in small teams, and help everyone in the class learn more about the country of study. This assignment allows the students to become more globally aware and to hone their knowledge of the specific country, so that they are well-informed travelers as well as global citizens. As assessed by a participant in the Korea program: "I left this trip as a more confident, independent traveler and I now have a more open mind toward international business, and the way other cultures do things." 
The X272 programs were designed to offer undergraduate students an opportunity to explore a country or region through the lens of international business in a short-term, immersive, on-site experiential study-abroad program. After 4 years of running X272 programs through which over 1,300 students have traveled abroad, Kelley faculty, staff, and student participants have heard and shared a variety of stories about the effects these programs have on individual students and on their subsequent undergraduate learning. Though the Kelley School has yet to take on a comprehensive assessment of student learning outcomes across the X272 programs, individual faculty directors who have run the programs in multiple iterations can attest to the dimensions of change they observed in student participants as well as what they learned themselves from one year to the next. One director recommends "being open to answer any questions throughout the experience, remembering for some students this is a first time." Overall, program directors need to be fully committed to the success of the X272 programs in a way that differs from traditional classroom learning, given that the group spends nearly all day, every day together while overseas.

This requirement for commitment is also true at the institutional level. The X272 programs would not have expanded as they did or even existed in the first place without the interest and support of the Kelley School leadership and the intentional development of a globally-focused business curriculum. The international focus is not exclusive to the Kelley School but is a longstanding priority for IU as a whole, making the institutions itself a key partner in the study abroad successes of its individual schools. As the Kelley School looks ahead to its sixth year of $\mathrm{X} 272$, the partnerships across the IU campus as well as the ongoing commitment from Kelley faculty, staff, and students will continue to open doors for Kelley undergraduates to experience business on a global scale. 


\section{References}

Benzing, C. (2005). Cuba-Is the "special period" really over? International Advances in Economic Research, 11(1), 69-82.

de Miranda-Parrondo, M. (2014). Current problems in the Cuban economy and necessary reforms (pp. 41-62). In C. Brundenius \& R. Torres-Pérez (Eds.), No more free lunch. New York, NY: Springer.

Kuh, G. D. (2008). High-impact educational practices: What they are, who has access to them, and why they matter. $A A C \& U$. Available at https://www.aacu.org/leap/hips

Norris, E. M., \& Gillespie, J. (2009). How study abroad shapes global careers: Evidence from the United States. Journal of Studies in International Education, 13(3), 382-397.

Peng, G. C. A., \& Nunes, M. B. (2007). Using PEST analysis as a tool for refining and focusing contexts for information systems research (pp. 229-236). In Proceedings of the Sixth European Conference on Research Methodology for Business and Management Studies. Sonning Common, UK: Academics Conference International.

Phillips, E. F. (2007). "Maybe tomorrow I'll turn capitalist:” Cuentapropismo in a workers' state. Law and Society Review, 41(2), 305-342.

Riera, O., \& Swinnen, J. F. M. (2016). Cuba's agricultural transition and food security in a perspective. Applied Economic Perspectives and Policy, 38(3), 413-448.

Tarrant, M., \& Lyons, K. (2012). The effect of short-term educational travel programs on environmental citizenship. Environmental Education Research, 18(3), 403-416.

United Nations Human Rights Council (UNHRC). (2011). Guiding principles on business and human rights: Implementing the United Nations 'Protect, Respect and Remedy' framework. Report of the Special Representative of the Secretary-General on the issue of human rights and transnational corporations and other business enterprises. Available at http://www.ohchr.org/Documents/Publications/GuidingPrinciplesBusinessHR_EN.pdf 